\title{
A cluster-based phosphor against thermal quenching via dynamic metallic bonding
}

Dayu Wu ( $\nabla$ wudy@cczu.edu.cn )

Changzhou University

Miao Li

Changzhou University

Huixian Miao

Changzhou University

Jing Wu

Changzhou University

\section{Zongsu Yu}

Changzhou University

Luying Liu

Changzhou University

\section{Wenjiang Zhaxi}

Changzhou University

\section{Xiao Ma}

Changzhou University

\section{Shenlong Jiang}

University of Science and Technology of China

\section{Qun Zhang}

University of Science and Technology of China https://orcid.org/0000-0002-5777-9276

Wei Huang

Changzhou University

\section{Xiancheng Pan}

University of Science and Technology of China

\section{Article}

Keywords:

Posted Date: February 14th, 2022

DOI: https://doi.org/10.21203/rs.3.rs-1357897/v1 
License: (c) (i) This work is licensed under a Creative Commons Attribution 4.0 International License. Read Full License 


\section{Abstract}

The effect of dynamic chemical bonding on material properties has long been the subject of intensive investigation in the fields of chemistry and materials. Especially, the dynamic metallic bonding is uncommon because the intermetallic electronic interaction may respond to external stimuli, which potentially builds the synergistic coupling among many physical properties. Herein, we experimentally investigate a dynamic $\mathrm{Cu}-\mathrm{Cu}$ bonding interaction that dictates the thermal quenching effect of photoluminescence $(\mathrm{PL})$ in a high-efficiency metal-halide cluster-based phosphor. The weakening of $\mathrm{Cu}$-Cu bonding in such a phosphor system enables the release of bonding electrons from $\mathrm{Cu}(\mathrm{I}) 3 d$-orbital and hence sustains the PL efficiency at high temperatures (up to $100^{\circ} \mathrm{C}$ ). The temperature-dependent structural, NMR and EPR measurements reveal a reversible transition from diamagnetic $\mathrm{Cu}(\mathrm{I})$ to paramagnetic $\mathrm{Cu}$ (II) species. The white light-emitting diodes (LEDs) incorporating the thermally stable phosphor show a rapid brightness rise even at a high bias current $(1,000 \mathrm{~mA})$ with color rendering index as high as 90 , comparable to the commercial phosphor-based prototype LEDs (e.g., YAG:Ce ${ }^{3+}$ ). This work establishes a novel prototype of cluster-based phosphor featuring dynamic metallic bonding, which paves the way for exploration of phosphor-converted LEDs against thermal quenching.

\section{Introduction}

Intermetallic bonding interactions in metallic clusters or molecules have attracted much attention in the past two decades due to their potential applications in many fields, including catalysis, photoluminescence, magnetism and so on. ${ }^{1}$ The metallic coinage clusters, such as copper $(\mathrm{Cu})$, silver $(\mathrm{Ag})$ and gold $(\mathrm{Au})$, demonstrated a great variety of structural forms and photophysical properties through $d-d$ interaction. ${ }^{2-4}$ Among them, the metal-halide clusters with the formula of $\left[\mathrm{M}_{4} \mathrm{X}_{4} \mathrm{~L}_{4}\right](\mathrm{M}=$ $\mathrm{Cu}(\mathrm{I}), \mathrm{X}=\mathrm{Cl}, \mathrm{Br}, \mathrm{I} ; \mathrm{L}=\mathrm{N}$ or P-terminal ligands) exhibit the prototype cubic cluster structure with copper and halide atoms occupying alternatively the corner of a cube..$^{5-10}$ The metallic bonding interaction makes this type of metallic cluster particularly attractive to develop new phosphor materials for applications in high-performance light-emitting diodes (LEDs) devices. ${ }^{11-13}$ Nevertheless, a critical challenge is the socalled thermal quenching (TQ) effect of luminescence at high temperatures. ${ }^{14-17}$ For instance, the temperature generated from Joule effect in gallium nitride LEDs can exceed $100^{\circ} \mathrm{C}$, at which the photoluminescence $(\mathrm{PL})$ will be almost quenched for traditional phosphors via the nonradiative relaxation of excited electrons to the ground state. ${ }^{18-20}$ The TQ effect severely collapses the efficiency and deteriorates the white balance of phosphor-converted white LEDs (pc-wLEDs). As such, the development of new mechanisms against the TQ effect remains an open challenge, which is highly desirable as it would bring new opportunities for the real-world applications of LEDs. ${ }^{21-24}$

In attempt to obtain high-efficiency PL materials, great efforts have been made to mitigate the detrimental TQ effect. ${ }^{25-32}$ In principle, TQ could be largely minimized through suppressing the possible energy loss via nonradiative relaxation channels in the solid state by rigid molecular conformations 
or dense packing structure. ${ }^{33-35}$ The understanding of the mechanisms behind TQ is rather beneficial for the predetermined design of highly photo-stable materials suitable for high-power LEDs

lighting (Supplementary Fig. 1). The incorporation of discrete metallic clusters into robust and extended network structures has been proven an efficient strategy to improve both thermal- and photo-

stabilities. ${ }^{36-38}$ Apart from the rigidification strategy, it is also known that metal-metal bonding interaction plays a crucial role in stabilizing the PL of metallic coinage compounds. The intermetallic interaction provides an alternative strategy that is promising for developing phosphor materials against TQ. ${ }^{39-41}$ Intriguingly, the reversible change of electronic coupling through the dynamic intermetallic bonding would bring about switchable properties in, e.g., metal-based luminescence and magneticism. ${ }^{42}$ Therefore, the identification of new dynamic intermetallic bonding systems that dictates multifunctional coupling at atomic level is a vital objective in the development of advanced molecular-based materials.

In this work, we report a copper-halide cluster-based coordination polymer, bppCu $\mathrm{I}_{4} \mathrm{P}_{4}(\mathrm{bpp}=1,3-$ bis(diphenylphosphino)propane), as a yellow-emitting phosphor that can well function against the TQ effect. The heating sustains its PL intensity (up to $100^{\circ} \mathrm{C}$ ) instead of PL reduction. The PL TQ driven by excess thermal energy is concomitant with spin flipping due to the weakening of intermetallic bonding interaction at high temperatures, demonstrating that the TQ effect can be well controlled via intermetallic bonding interaction for high-power LEDs applications.

\section{Results And Discussion}

Electronic structural transition. Reaction of organophosphate terminal ligand (bpp) with Cul under a solvothermal condition yielded colorless block crystals of bppCu $\mathbf{I}_{4} \mathrm{P}_{\mathbf{4}}$ (Supplementary Fig. 2). The singlecrystal sample was phase-pure, as evidenced by powder XRD pattern and element microanalysis. Given that the two phosphine atoms on the terminals of bpp can link the neighboring clusters through strong $\mathrm{Cu}-\mathrm{P}$ bonds, the thermal stability of the crystalline $\mathrm{bppCu}_{4} \mathrm{I}_{4} \mathrm{P}_{4}$ sample was significantly enhanced (Supplementary Fig. 3), as compared to those of the discrete structures. ${ }^{43,44}$ Single-crystal X-ray diffraction at $100 \mathrm{~K}$ revealed that bppCu${ }_{4} \mathrm{I}_{4} \mathrm{P}_{4}$ crystallizes in the monoclinic $P 2 / \mathrm{c}$ space group and the asymmetric unit contains one and two halves of crystallographically distinct $\mathrm{Cu}_{4} \mathrm{I}_{4}$ clusters and four bpp ligands, respectively (Fig. 1 and Supplementary Table 1). In the structure of $\mathrm{bppCu}_{4} \mathrm{I}_{4} \mathrm{P}_{4}$, the cubic $\mathrm{Cu}_{4} \mathrm{I}_{4}$ clusters are interlinked via terminal $\mathrm{Cu}-\mathrm{P}$ bonds by a pair of bpp ligands, giving rise to a onedimensional (1D) cluster chain. The 1D chains are further extended into two-dimensional framework by $\pi \ldots \pi$ stacking interactions with the shortest interatomic distance of $3.465 \AA$. These intermolecular interactions synergistically rigidify the metal-organic framework, which favors the additional structural stability at high temperatures. ${ }^{45-51}$

Both single-crystal and powder XRD patterns of bppCu $\mathrm{b}_{4} \mathrm{P}_{4}$ revealed a reversible structural transformation with changing temperature (Fig. 2a and Supplementary Fig. 4, 5). At $298 \mathrm{~K}$, the diffraction at $\sim 10^{\circ}$ shows a distinct doublet peak, while they began to merge with increasing temperature. The 
structural change at high temperatures was confirmed by the shifts in the diffraction peaks of $\sim 14.8$, 23.2 and $30.8^{\circ}$ to the lower Bragg angles, as compared to the structure at room temperature (R.T.). Electronic absorption spectra at different temperatures indicated that the ligand's electronic structure was undisturbed upon heating (Supplementary Fig. 6). The structural transition is related to the elongation of intracluster $\mathrm{Cu}$ - $\mathrm{Cu}$ distance in the crystal lattice. As the temperature increases, the excess thermal energy drives the weakening of intermetallic bonding interaction and the elongation of $\mathrm{Cu}-\mathrm{Cu}$ distance. Raman spectra in the region of $500-3500 \mathrm{~cm}^{-1}$ turned out to be similar at different temperatures (Supplementary Fig. 7), which correspond to the phosphine ligand, in accordance with IR analyses. In the low-frequency region, the bands below $100 \mathrm{~cm}^{-1}$ are attributed to normal vibrational modes of $\mathrm{Cu}-\mathrm{I}$ stretching. The additional band at $130 \mathrm{~cm}^{-1}$ is responsible for $\mathrm{Cu}-\mathrm{Cu}$ vibrations (breathing). The weak peak at $220 \mathrm{~cm}^{-1}$ is assigned to the $\mathrm{Cu}-\mathrm{P}$ stretching. These observations are consistent with both the experimental and calculated results on these cubane clusters. ${ }^{52}$ With increasing temperature above 300 $\mathrm{K}$, the band below $100 \mathrm{~cm}^{-1}$ continues to grow in its strength, especially, a new peak appears at ca. 35 $\mathrm{cm}^{-1}$, alongside with the reduction of the band at $130 \mathrm{~cm}^{-1}$. These results indicated that thermal stimuli essentially impact the intracluster bonding interactions and give rise to the stronger $\mathrm{Cu}-\mathrm{I}$ ionic bonds and weaker coprophilic $\mathrm{Cu}-\mathrm{Cu}$ interactions.

To probe the temperature dependence of coprophilic $\mathrm{Cu}$ - $\mathrm{Cu}$ interactions, the $\mathrm{X}$-ray diffraction analyses were performed on an individual single crystal in the temperature sequence of $100 \rightarrow 200 \rightarrow 250 \rightarrow 300 \rightarrow 325 \rightarrow 350 \rightarrow 375 \rightarrow 400 \rightarrow 100 \mathrm{~K}$. The space group changed from $\mathrm{P} 2 / \mathrm{c}$ at $100 \mathrm{~K}$ to $\mathrm{C} 2 / \mathrm{c}$ at temperatures higher than $200 \mathrm{~K}$. The shortest $\mathrm{Cu}-\mathrm{Cu}$ bond distances are provided in Fig. $2 \mathrm{~b}$ and the results are completely reversible in heating/cooling cycles (Supplementary Table 2). While the $\mathrm{Cu}-\mathrm{P}$ and $\mathrm{Cu}-\mathrm{I}$ bond distances are quite similar at different temperatures, the $\mathrm{Cu}-\mathrm{Cu}$ interactions are clearly temperature-dependent. At $100 \mathrm{~K}$, the $\mathrm{Cu}$ - Cu distances, such as 2.7418(7) $\AA$ for $\mathrm{Cu} 1$ - Cu3 and 2.7570(6) $\AA$ for $\mathrm{Cu} 5$ - Cu6, in the $\mathrm{bppCu}_{4} \mathrm{I}_{4} \mathrm{P}_{4}$ cluster are shorter than the sum of the van der Waals radii of copper(I) $(2.80 \AA)$, suggesting significant cuprophilic bonding interaction $\left(d^{10}-d^{10}\right)$ at this temperature. Upon heating the crystal, the $\mathrm{Cu}-\mathrm{Cu}$ distance shows a quasi-linear increase and approaches beyond the cuprophilic bonding interaction. The results suggested that the heating can gradually induce the weakening of $\mathrm{Cu}-\mathrm{Cu}$ bonding interaction (Fig. 2c).

To investigate the dynamic electronic structure induced by the weakening of bonding interactions, solidstate ${ }^{63} \mathrm{Cu}$ WURST-QCPMG and CPMAS ${ }^{31} \mathrm{P}$ NMR spectra were recorded at different temperatures. The compound of bppCu $\mathbf{b}_{4} \mathrm{I}_{4}$ exhibited a particularly wide span of ${ }^{63} \mathrm{Cu}$ static NMR spectra at $298 \mathrm{~K}$, as compared to the similar $\left[\mathrm{Cu}_{4} \mathrm{I}_{4}\right]$ cubane structure, ${ }^{52,53}$ and hence the individual components were poorly resolved (Fig. 2d). As temperature increased, the ${ }^{63} \mathrm{Cu}$ NMR patterns began to be weak. At $373 \mathrm{~K}$, the ${ }^{63} \mathrm{Cu}$ NMR signals cannot be detected, which is likely induced by the paramagnetic $\mathrm{Cu}(\mathrm{II})$ or free electrons. The assumption was further supported by the ${ }^{31} \mathrm{P}$ NMR spectra. Considering the $J$ couplings between one ${ }^{31} \mathrm{P}$ atom and two copper isotopes $\left({ }^{65} \mathrm{Cu}\right.$ and ${ }^{63} \mathrm{Cu}$ of $I=3 / 2$ with natural abundance of $30.8 \%$ and $69.2 \%$, respectively), four quartets can be expected with two crystallographically independent phosphorus sites 
in bppCu $\mathbf{u}_{4} \mathrm{I}_{4} \mathrm{P}_{4}$. As shown in Supplementary Fig. 8, bppCu${ }_{4} \mathrm{I}_{4} \mathrm{P}_{\mathbf{4}}$ exhibited highly overlapped ${ }^{31} \mathrm{P}$ NMR resonances at $298 \mathrm{~K}$ due to quite similar phosphorus environment, which originates from the $J$ couplings of ${ }^{31} \mathrm{P}-{ }^{63} \mathrm{Cu}$ and ${ }^{31} \mathrm{P}-{ }^{65} \mathrm{Cu}$. We attempted to deconvolute the ${ }^{31} \mathrm{P}$ NMR spectrum using a dmfit software, but the software algorithm was limited in the presence of paramagnetic species. The ${ }^{31} \mathrm{P}$ NMR spectrum at $323 \mathrm{~K}$ showed an electronic structure similar to that of $298 \mathrm{~K}$ with a slight shift and broadening of the peaks. However, upon further heating the sample to $373 \mathrm{~K}$, the increasing amount of paramagnetic species resulted in a significant broadening of its half peak width and a decrease of $J$ coupling. This result highlighted the sensitivity of the MAS ${ }^{31} \mathrm{P}$ NMR technique to detect the temperature dependence of electronic structures, thereby allowing us to state that the heating treatment can effectively induce electronic structural transition. As the $\mathrm{Cu}-\mathrm{Cu}$ interactions in the excited states are of bonding character, the PL emission should be correlated to the $\mathrm{Cu}-\mathrm{Cu}$ distances in the discrete metallic clusters. ${ }^{54}$

Zero-TQ property and mechanism. The $\mathrm{PL}$ spectra of $\mathrm{bppCu}_{4} \mathrm{I}_{4} \mathrm{P}_{4}$ at $298 \mathrm{~K}$ revealed a single broad yellow emission band with a peak at ca. $600 \mathrm{~nm}$ arising from the cluster-centered $\left({ }^{3} \mathrm{CC}\right)$ low-energy (LE) band common for $\left[\mathrm{Cu}_{4} \mathrm{I}_{4} \mathrm{~L}_{4}\right]$-type clusters, ${ }^{55-59}$ with a full-width at half-maximum (FWHM) of $\sim 84 \mathrm{~nm}$ under $355 \mathrm{~nm}$ excitation and an absolute PL quantum yield (PLQY) of 80\% (Fig. 3a and Supplementary Fig. 9). While some spectral parameters (including FWHM and PLQY) of $b_{p p C u_{4}} \mathrm{I}_{4} \mathrm{P}_{4}$ are close to those of commercial yellow phosphors (such as YAG: $\mathrm{Ce}^{3+}$ and $(\mathrm{Sr}, \mathrm{Ba})_{2} \mathrm{SiO}_{4}: \mathrm{Eu}^{2+}$ ), the emission spectra of bppCu${ }_{4} \mathrm{I}_{4} \mathrm{P}_{4}$ showed a sufficient red component. Thus, the $\mathrm{bppCu}_{4} \mathrm{I}_{4} \mathrm{P}_{4}$-based WLED device is expected to have high color rendering index (CRI) (>80) and low correlated color temperature (CCT) $(<4500 \mathrm{~K})$. The strong electronic absorption in the near-ultraviolet (NUV) as well as its intense yellow emission make it potential as an NUV white LED. ${ }^{60-64}$ Upon heating from R.T., bppCu $\mathbf{I}_{4} \mathrm{P}_{4}$ exhibited a thermally stable emission (i.e., zero-TQ PL), without obvious emission loss up to a temperature of $378 \mathrm{~K}$ under $\lambda_{\mathrm{ex}}=355$ $\mathrm{nm}$ (Fig. $3 \mathrm{c}, \mathrm{d})$. The variation of the $\mathrm{Cu}-\mathrm{Cu}$ bond distances seemed to be insufficient to induce modification of the corresponding emissive state. The zero-TQ PL was also reflected in the temperaturedependent PL excitation spectrum (Supplementary Fig. 10).

To reveal the nature of excited states, the time-resolved PL spectroscopy was conducted at $298 \mathrm{~K}$ (Supplementary Fig. 11). The LE-band decay curve of $\mathrm{bppCu}_{4} \mathrm{I}_{4} \mathrm{P}_{4}$ can be well fitted by a singleexponential function, yielding a lifetime $(\tau)$ of $5.0 \mu \mathrm{s}$, which suggests that an efficient phosphorescence occurs at R.T. To further unveil the nature of excited states, temperature-dependent femtosecond timeresolved transient absorption (fs-TA) spectra were recorded (Supplementary Fig. 12). The fs-TA kinetic decays of bppCu${ }_{4} \mathrm{I}_{4} \mathrm{P}_{4}$ turned out to hold a nearly identical constant of ca. $5.0 \mu \mathrm{s}$ in the range of $78-350$ $\mathrm{K}$ (Fig. 3 e). Such a temperature independence precludes the possibility of thermally activated delayed fluorescence and confirms that a ${ }^{3} \mathrm{CC}$ excited state is operative in the detected temperature region.

To gain deeper insights into the mechanism behind the TQ effect, electron paramagnetic resonance (EPR) spectroscopy as a sensitive technique was undertaken in situ at varied temperatures (Fig. 4a). At 298 K, the complex of bppCu${ }_{4} \mathrm{I}_{4} \mathrm{P}_{4}$ exhibited a weak and broad EPR absorption spectra. As the temperature 
increased, however, the absorption of EPR spectra became intense and narrow in linewidth, echoing well to the NMR result mentioned above. These observations demonstrated that $\mathrm{Cu}-\mathrm{Cu}$ bonding interaction at $298 \mathrm{~K}$ can lead to the localized bonding electron pairs on the $3 d$ - and $4 s$-orbitals following orbital hybridization according to the classical valence-bonding theory, as illustrated in Fig. 4b. However, in the absence of appreciable $d-d$ interaction, the $3 d$-electrons are expected to be unpaired and hence poorly bonding (or with free electrons emerging). Accordingly, the spin state of the $\mathrm{Cu}$ ion is sensitive to the $\mathrm{Cu}-$ $\mathrm{Cu}$ distance. Indeed, as the $\mathrm{Cu}-\mathrm{Cu}$ distance continued to increase upon heating, the EPR signal at $373 \mathrm{~K}$ began to show the characteristic of $\mathrm{Cu}^{2+}$ complex with an isotropic $g \sim 2.1 .^{65}$ The result is reminiscent of some Cu complexes in which spin flipping was observed both experimentally and computationally upon increasing (ca. $0.1 \AA)$ in the $\mathrm{Cu}-\mathrm{Cu}$ distance. ${ }^{66,67}$

According to the energy level diagram for the lowest states, the $\mathrm{Cu}_{4} \mathbf{l}_{4} \mathrm{P}_{\mathbf{4}}$ cluster exhibits two separate excited states of ${ }^{3} \mathrm{CC}\left(T_{1}\right)$ and ${ }^{3} \mathrm{MLCT} /{ }^{3} \mathrm{XLCT}\left(T_{2}\right)$ below R.T. (Supplementary Fig. 13). As temperature increases from $78 \mathrm{~K}$ to R.T., the ${ }^{3} \mathrm{CC}$ state is progressively populated the expense of ${ }^{3} \mathrm{XLCT} /{ }^{3} \mathrm{MLCT}$ thanks to the increase of vibrational energies. The stabilized PL intensity from R.T. to $100^{\circ} \mathrm{C}$ under 355 $\mathrm{nm}$ excitation was the consequence of weak intermetallic bonding interaction. ${ }^{68}$ The $\mathrm{Cu}-\mathrm{Cu}$ elongation is not sufficient to induce changes in the energy of the $T_{1}$ state and consequently of the LE emission band. However, the higher temperature ( $>373 \mathrm{~K}$ ) facilitates electronic structural transition from the bonding state to the non-bonding state, i.e., the release of bonding electrons, and a high concentration of $\mathrm{Cu}^{2+}$ species arises as a consequence of spin flipping. These paramagnetic species can be effectively transmitted between the neighboring clusters through covalent-linked cluster polymerization, giving rise to an emission reduction above $100^{\circ} \mathrm{C}$.

Performance of wLEDs. High-power LEDs lighting is a crucial challenge due to the significant TQ under a high flux operating current. Considering the unusual zero-TQ property in the wide temperature range, we investigated the high-power LEDs performance of the $\mathrm{bppCu}_{4} \mathrm{l}_{4} \mathrm{P}_{4}$ phosphor with an NUV LEDs chip $\left(\lambda_{\max }\right.$ $=365 \mathrm{~nm}$ ). The results of single-component and white-light LEDs are shown in Fig. 5 and Supplementary Fig. 14. The electroluminescence (EL) intensities of the yellow-emitting bppCu $\mathbf{L}_{4} \mathbf{P}_{4}$ phosphor and commercial yellow-emitting phosphors (such as YAG: $\mathrm{Ce}^{3+}$ and $(\mathrm{Sr}, \mathrm{Ba})_{2} \mathrm{SiO}_{4}: \mathrm{Eu}^{2+}$ ) increased with a low current below $300 \mathrm{~mA}$ (Fig. 5a,b and Supplementary Fig. 15). The bppCu $\mathbf{H}_{4} \mathrm{I}_{4}$-based LED exhibited superior EL intensities above $300 \mathrm{~mA}$, while the $\mathrm{EL}$ intensities of commercial $(\mathrm{Sr}, \mathrm{Ba})_{2} \mathrm{SiO}_{4}: \mathrm{Eu}^{2+}$ decreased above $300 \mathrm{~mA}$, due to the serious TQ effect (Supplementary Table 3). For bppCu $\mathbf{~}_{4} \mathrm{I}_{4} \mathrm{P}_{4}$-based white LED (BAM:Eu ${ }^{2+}$ as the blue component), the EL spectra covered the whole visible region from 400 to $750 \mathrm{~nm}$ (i.e., a white-light emission) and the EL intensities increased in the range of 100-1,000 mA. In contrast, the YAG:Ce ${ }^{3+}$-based wLED showed a reduced EL, especially at high currents (Fig. $5 \mathrm{C}$ ).

To demonstrate the potential of practical applications as wLED devices, the colour stability during highpower LED operation were recorded. ${ }^{69}$ The CIE $x(c a .0 .35)$ of bppCu $\mathrm{b}_{4} \mathrm{I}_{4} \mathrm{P}_{4}$-based WLED remained basically unchanged, despite CIE $y$ showed a slight shift from 0.31 to 0.35 in the range of high flux current of 100- 
1,000 mA (Fig. 5d and Supplementary Table 4 - 6). The CRI value of $\mathrm{bppCu}_{4} \mathrm{I}_{4} \mathrm{P}_{4}$-based $w L E D$ was as high as 90 with a CCT of $4809 \mathrm{~K}$ at a flux current of 1,000 mA. The low CCT and high CRI value showed the excellent optical properties of cluster-based phosphor at a high flux current. The fabricated $\mathrm{bppCu}_{4} \mathrm{I}_{4} \mathrm{P}_{4^{-}}$ based LED (Fig. 5e) exhibited a bright yellow emission at an applied current of 1,000 mA. It should be noted the wLED exhibited comparable white emission to the commercial YAG:Ce ${ }^{3+}$ (Fig. 5f,g). These results demonstrated that $\mathrm{bppCu}_{4} \mathrm{I}_{4} \mathrm{P}_{4}$ is a robust phosphor that can well function against the TQ effect, making it potentially ideal as a yellow-emitting phosphor for high-power white LEDs lighting.

\section{Conclusion}

In summary, we have synthesized, experimentally characterized and comprehensively revealed a previously unreported metal-halide cluster-based phosphor, which exhibited zero-TQ phosphorescence via dynamic metallic bonding. On the basis of single-crystal material, temperature-dependent PL and fsTA spectroscopy demonstrated the high thermally stable phosphorescence. Temperature-dependent XRD, NMR and EPR characterizations demonstrated the presence of a diamagnetic-to-paramagnetic transition at around $100^{\circ} \mathrm{C}$, which is concomitant with the thermal quenching of phosphorescence. This new class of materials will build the foundation for exploiting dynamic intermetallic bonding interaction as an effective means to control the emission stability of phosphors.

\section{Declarations}

Acknowledgments: We are thankful for financial support from the PAPD of Jiangsu Higher Education Institutions. This work was supported by the National Natural Science Foundation of China (92161121, 22173090, 91950207, 21573211), the National Key Research and Development Program of China (2018YFA0208702, 2016YFA0200602), the Anhui Initiative in Quantum Information Technologies (AHY090200), the USTC Key Directions Project Incubation Fund (WK2340000106) and the USTC-NSRL Joint Funds (UN2018LHJJ).

Author contribution: D.W. conceived and supervised the project. M.L. and H.M. grew the single crystals. X.P., S.J. and Q.Z. conducted and analyzed Raman, fs-TA, NMR and EPR. J.W. and Z.Y. conducted and analyzed single-crystal XRD. L.L. and X.M. conducted and analyzed temperature-dependent powder XRD. X.M., Z.W. and W.H fabricated LED devices. W.H. and D.W. wrote the manuscript. W.H., S.J., Q.Z. and D.W. participated in data analysis and discussion.

Competing interests: The authors declare that they have no competing interests.

Data and materials availability: All data needed to evaluate the conclusions in the paper are present in the paper and/or the Supplementary Materials. Additional data related to this paper may be requested from the authors.

\section{References}


1. Li J, Li X, Zhai H-J, Wang L-S (2003) Au 20 : A Tetrahedral Cluster. Science 299:864-867

2. Jena P, Castleman AW Jr, Clusters (2006) : A bridge across the disciplines of physics and chemistry. Proc. Natl. Acad. Sci. U. S. A. 103, 10560 - 10569

3. Takano S, Hirai H, Nakashima T, Iwasa T, Taketsugu T, Tsukuda T (2021) Photoluminescence of Doped Superatoms $M @ A_{12}\left(M=R u, R h\right.$, Ir) Homoleptically capped by $\left(\mathrm{Ph}_{2}\right) \mathrm{PCH}_{2} \mathrm{P}\left(\mathrm{Ph}_{2}\right)$ : efficient room-temperature phosphorescence from Ru@Au ${ }_{12}$. J Am Chem Soc 143:10560-10564

4. Yam VW-W, Au VK-M, Leung SY-L (2015) Light-Emitting Self-Assembled Materials Based on $d^{8}$ and $d^{10}$ Transition Metal Complexes. Chem Rev 115:7589-7728

5. He QT, Li XP, Liu Y, Yu ZQ, Wang W, Su CY (2009) Copper(I) cuboctahedral coordination cages: hostguest dependent redox activity. Angew Chem Int Ed 48:6156-6159

6. Kong YJ et al (2020) Photoresponsive propeller-like chiral AIE copper(I) clusters. Angew Chem Int Ed 59:5336-5340

7. Liu W et al (2017) All-in-one: Achieving robust, strongly luminescent and highly dispersible hybrid materials by combining ionic and coordinate bonds in molecular crystals. J Am Chem Soc 139:9281-9290

8. Wang J-J et al (2020) Highly luminescent copper iodide cluster based inks with photoluminescence quantum efficiency exceeding 98\%. J Am Chem Soc 142:3686-3690

9. Evariste $S$ et al (2018) Adaptive coordination-driven supramolecular syntheses toward new polymetallic $\mathrm{Cu}(\mathrm{I})$ luminescent assemblies. J Am Chem Soc 140:12521-12526

10. Gong Q et al (2014) Solution Processable MOF Yellow Phosphor with Exceptionally High Quantum Efficiency. J Am Chem Soc 136:16724-16727

11. Zhang $X$ et al (2014) Systematic approach in designing rare-earth-free hybrid semiconductor phosphors for general lighting applications. J Am Chem Soc 136:14230-16236

12. Liu W, Fang Y, Li J (2018) Copper iodide based hybrid phosphors for energy-efficient general lighting technologies. Adv Funct Mater 28:1705593

13. Leitl MJ, Kuchle FR, Mayer HA, Wesemann L, Yersin H (2013) Brightly blue and green emitting $\mathrm{Cu}(\mathrm{I})$ dimers for singlet harvesting in OLEDs. J Phys Chem A 117:11823-11836

14. Kim YH A zero-thermal-quenching phosphor. Nat. Mater. 16, 543 - 550 et al (2017)

15. Barkaoui H et al (2019) Negative Thermal Quenching of Efficient White-Light Emission in a 1D Ladder-Like Organic/Inorganic Hybrid Material. Adv Opt Mater 7:201900763

16. Liu SY, Fang XY, Lu B, Yan DP (2020) Wide range zero-thermal-quenching ultralong phosphorescence from zero-dimensional metal halide hybrids. Nat Commun 11:4649

17. Zhang BB et al (2020) Antithermal Quenching of Luminescence in Zero-Dimensional Hybrid Metal Halide Solids. J Phys Chem Lett 11:2902-2909

18. Zhang LLM et al (2019) Core-dependent properties of copper nanoclusters: valence-pure nanoclusters as NIR TADF emitters and mixed-valence ones as semiconductors. Chem Sci 10:10122-10128 
19. Yu MX et al (2020) Constructing multi-cluster copper(i) halides using conformationally flexible ligands. Chem Commun 56:7233-7236

20. Wang J-J et al (2021) Chiral Phosphine-Copper lodide Hybrid Cluster Assemblies for Circularly Polarized Luminescence. J Am Chem Soc 143:10860-10864

21. Yao J-S, Wang J-J, Yang J-N, Yao H-B (2021) Modulation of Metal Halide Structural Units for Light Emission. Acc Chem Res 54:441-451

22. Lin F, Wang H, Lin H, Liu W, Li J (2021) An antimony based organic-inorganic hybrid coating material with high quantum efficiency and thermal quenching effect. Chem Commun 57:1754-1757

23. Kitagawa H, Ozawa Y, Toriumi K (2010) Flexibility of cubane-like Cu4I4 framework: temperature dependence of molecular structure and luminescence thermochromism of [Cu4I4(PPh3)4] in two polymorphic crystalline states. Chem Commun 46:6302-6304

24. Benito Q et al (2015) Geometry flexibility of copper iodide clusters: variability in luminescence thermochromism. Inorg Chem 54:4483-4494

25. Wu T et al (2020) Negative thermal quenching of photoluminescence in a copper-organic framework emitter. Chem Commun 56:12057-12060

26. Li M et al (2021) Negative/Zero Thermal Quenching of Luminescence via Electronic Structural Transition in Copper-lodide Cluster-Based Coordination Networks. J Phys Chem Lett 12:8237-8245

27. Schinabeck A, Leitl MJ, Yersin H (2018) Dinuclear Cu(I) Complex with Combined Bright TADF and Phosphorescence. Zero-Field Splitting and Spin-Lattice Relaxation Effects of the Triplet State. J. Phys. Chem. Lett. 9, $2848-2856$

28. Li S, Dong X-Y, Qi K-S, Zang S-Q, Mak TCW (2021) Full-Color Tunable Circularly Polarized Luminescence Induced by the Crystal Defect from the Co-assembly of Chiral Silver(I) Clusters and Dyes. J Am Chem Soc 143:49, 20574-20578

29. Liu W et al (2015) A Family of Highly Efficient Cul-Based Lighting Phosphors Prepared by a Systematic, Bottom-up Synthetic Approach. J Am Chem Soc 137:9400-9408

30. Li J-J, Liu Z, Guan Z-J, Han X-S, Shi W-Q, Wang QM (2022) A 59-Electron Non-Magic-Number Gold Nanocluster Au. Show Unexpectedly High Stab J Am Chem Soc 144:690-694

31. Shan XC et al (2013) Using cuprophilicity as a multi-responsive chromophore switching color in response to temperature, mechanical force and solvent vapors. J Mater Chem C 1:4339-4349

32. Czerwieniec R, Kowalski K, Yersin H (2013) Highly efficient thermally activated fluorescence of a new rigid $\mathrm{Cu}(\mathrm{I})$ complex $[\mathrm{Cu}(\mathrm{dmp})$ (phanephos)]+. Dalton Trans 42:9826-9830

33. Tang Y, Wu HL, Cao WQ, Cui YJ, Qian GD (2020) Luminescent Metal-Organic Frameworks for White LEDs. Adv Opt Mater 9:202001817

34. Fang Y et al (2016) J. A Systematic Approach to Achieving High Performance Hybrid Lighting Phosphors with Excellent Thermal- and Photostability. Adv Funct Mater 27:201603444

35. Tan $\mathrm{X}$ et al (2012) Three-Dimensional Phosphine Metal-Organic Frameworks Assembled from $\mathrm{Cu}(\mathrm{I})$ and Pyridyl Diphosphine. Chem Mater 24:480-485 
36. Lustig WP et al (2020) Rational design of a high-efficiency, multivariate metal-organic framework phosphor for white LED bulbs. Chem Sci 11:1814-1824

37. Zhu K et al (2021) A new type of hybrid copper iodide as nontoxic and ultrastable LED emissive layer material. ACS Energy Lett 6:2565-2574

38. Hei X et al (2020) Blending lonic and Coordinate Bonds in Hybrid Semiconductor Materials: A General Approach toward Robust and Solution-Processable Covalent/Coordinate Network Structures. J Am Chem Soc 142:4242-4253

39. Chen $\mathrm{C}$ et al (2018) Highly Luminescent Inks: Aggregation-Induced Emission of Copper-lodine Hybrid Clusters. Angew Chem Int Ed 57:7106-7110

40. Xie M, Han C, Liang Q, Zhang J, Xie G, Xu H (2019) Highly efficient sky blue electroluminescence from ligand-activated copper iodide clusters: Overcoming the limitations of cluster light-emitting diodes. Sci Adv 5:eaav9857

41. Huitorel B et al (2018) Evaluation of Ligands Effect on the Photophysical Properties of Copper lodide Clusters. Inorg Chem 57:4328-4339

42. Huang W, Ma X, Sato O, Wu D (2021) Controlling dynamic magnetic properties of coordination clusters via switchable electronic configuration. Chem Soc Rev 50:6832-6870

43. Perruchas $S$ et al (2020) Mechanochromic and Thermochromic Luminescence of a Copper lodide Cluster. J Am Chem Soc 142:4242-4253

44. Benito Q et al (2014) Polymorphic Copper lodide Clusters: Insights into the Mechanochromic Luminescence Properties. J Am Chem Soc 136:32, 11311-11320

45. Wang SX et al (2020) Tunable Luminescence in Hybrid $\mathrm{Cu}(\mathrm{I})$ and $\mathrm{Ag}(\mathrm{I})$ lodides. Inorg Chem 59:15487-15494

46. Yu MX et al (2020) Constructing multi-cluster copper(i) halides using conformationally flexible ligands. Chem Commun 56:7233-7236

47. Kirakci K, Fejfarova K, Martincik J, Nikl M, Lang K (2017) Tetranuclear Copper(I) lodide Complexes: A New Class of X-ray Phosphors. Inorg Chem 56:4610-4615

48. Liu ZW, Djurovich PI, Whited MT, Thompson ME (2012) Cu4I4 clusters supported by $\mathrm{P}^{\wedge} \mathrm{N}$-type ligands: new structures with tunable emission colors. Inorg Chem 51:230-236

49. Naik S, Mague JT, Balakrishna MS (2014) Short-Bite PNP ligand-supported rare tetranuclear [Cu4I4] clusters: structural and photoluminescence studies. Inorg Chem 53:3864-3873

50. Taylor WV, Soto UH, Lynch VM, Rose MJ (2016) Antimony-Supported Cu4I4 Cuboid with Short Cu-Cu Bonds: Structural Premise for Near-Infrared Thermoluminescence. Inorg Chem 55:3206-3208

51. Knorr M et al (2015) Reactivity of Cul and CuBr toward dialkyl sulfides RSR: from discrete molecular Cu4I4S4 and Cu818S6 clusters to luminescent copper(I) coordination polymers. Inorg Chem 54:4076-4093

52. Utrera-Melero R et al (2020) Combining Theory and Experiment to Get Insight into the Amorphous Phase of Luminescent Mechanochromic Copper lodide Clusters. Inorg Chem 59:13607-13620 
53. Armaroli N, Accorsi G, Cardinali F, Listorti A (2007) Photochemistry and Photophysics of Coordination Compounds: Copper. In Photochemistry and Photophysics of Coordination Compounds I, pp $69-115$

54. Fu WF, Gan X, Che CM, Cao QY, Zhou ZY, Zhu NN (2004) Cuprophilic interactions in luminescent copper(I) clusters with bridging bis(dicyclohexylphosphino)methane and iodide ligands: spectroscopic and structural investigations. Chem -Eur J 10:2228-2236

55. Perruchas $S$ et al (2011) Thermochromic luminescence of copper iodide clusters: the case of phosphine ligands. Inorg Chem 50:10682-10692

56. Stollenz M, Raymond JE, Perez LM, Wiederkehr J, Bhuvanesh N (2016) Highly Luminescent Linear Complex Arrays of up to Eight Cuprous Centers. Chem -Eur J 22:2396-2405

57. Fang $Y$ et al (2019) Highly efficient and very robust blue-excitable yellow phosphors built on multiplestranded one-dimensional inorganic-organic hybrid chains. Chem Sci 10:5363-5372

58. Xu K et al (2020) From a blue to white to yellow emitter: a hexanuclear copper iodide nanocluster. Dalton Trans 49:5859-5868

59. Bai SQ, Jiang L, Young DJ, Andy Hor TS (2015) Luminescent [Cu(4)I(4)] aggregates and [Cu(3)I(3)]cyclic coordination polymers supported by quinolyl-triazoles. Dalton Trans 44:6075-6081

60. Shan XC et al (2013) A multi-metal-cluster MOF with Cu4I4 and Cu6S6 as functional groups exhibiting dual emission with both thermochromic and near-IR character. Chem Sci 4:1484-1489

61. Knorr M et al (2009) Rigidity effect of the dithioether spacer on the size of the luminescent cluster $(\mathrm{Cu}(2) \mathrm{I}(2))(\mathrm{n})(\mathrm{n}=2,3)$ in their coordination polymers.Dalton Trans. $948-955$

62. Yao L et al (2020) Circularly Polarized Luminescence from Chiral Tetranuclear Copper(I) lodide Clusters. J Phys Chem Lett 11:1255-1260

63. Hei X, Li J (2021) All-in-one: a new approach toward robust and solution-processable copper halide hybrid semiconductors by integrating covalent, coordinate and ionic bonds in their structures. Chem Sci 12:3805-3817

64. Wu Y, Wang JY, Zhang LY, Xu LJ, Chen ZN (2020) Vapor-triggered Green-to-Yellow Luminescence Conversion due to the Variation of Ligand Orientations in Tetranuclear Copper(I) Complex. Inorg Chem 59:17415-17420

65. Godiksen A et al (2014) Coordination Environment of Copper Sites in Cu-CHA Zeolite Investigated by Electron Paramagnetic Resonance. J Phys Chem C 118:23126-23138

66. Hendon $\mathrm{CH}$, Walsh $\mathrm{A}$ (2015) Chemical principles underpinning the performance of the metal-organic framework HKUST-1. Chem Sci 6:3674-3683

67. Butler KT, Hendon CH, Walsh A (2014) Electronic Chemical Potentials of Porous Metal-Organic Frameworks. J Am Chem Soc 136:2703-2706

68. Launay J-P, Verdaguer M (2018) Electrons in Molecules: From Basic Principles to Molecular Electronics. Oxford Univ. Press, UK 
69. Ki W, Li JA, Semiconductor Bulk (2008) Material That Emits Direct White Light. J Am Chem Soc 130:8114-8115

\section{Figures}

a

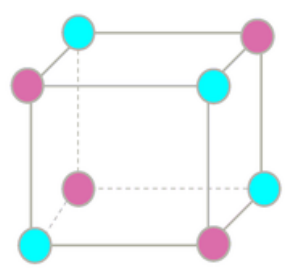

MHC discrete

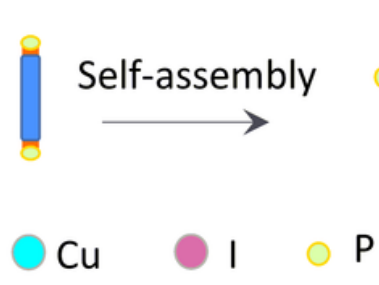

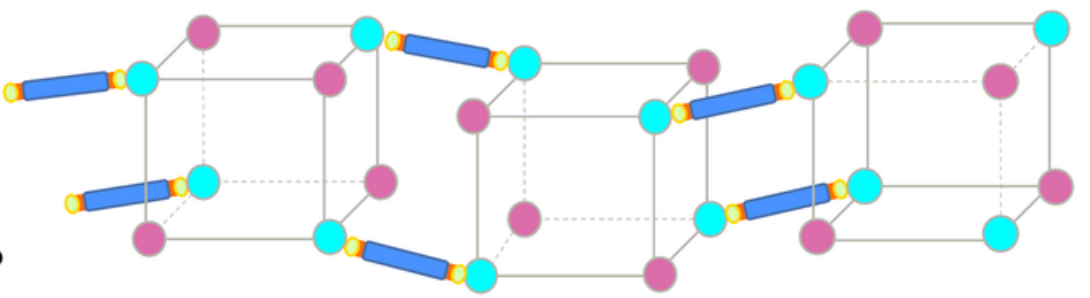

MHC-linked polymer

b
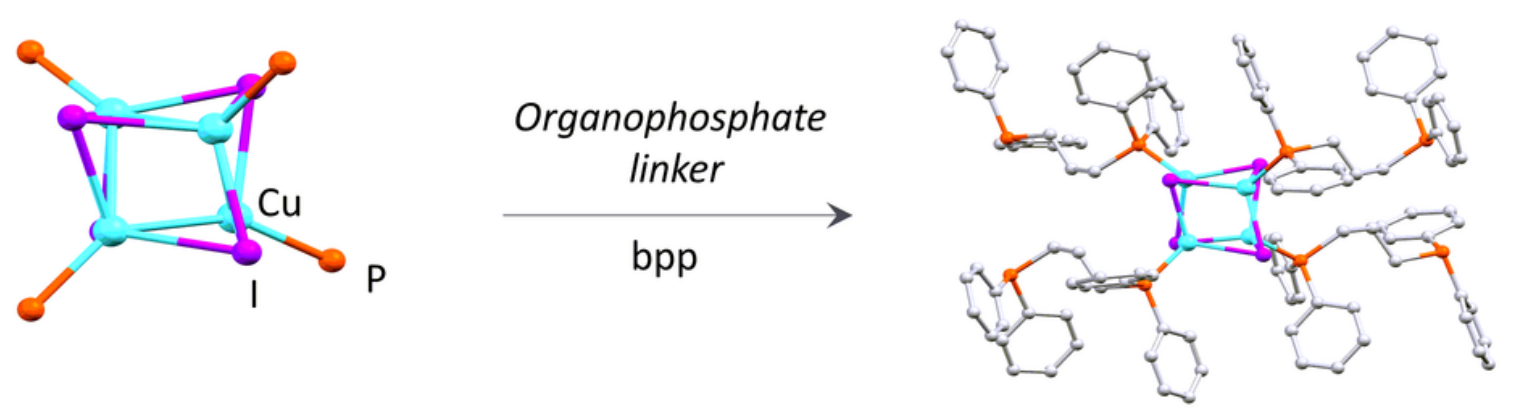

C

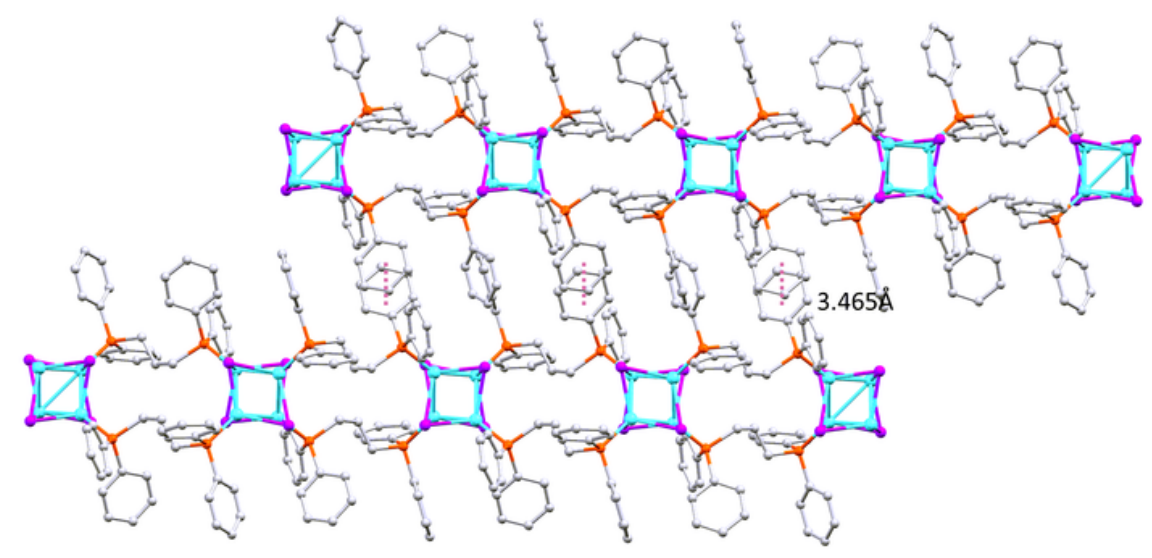

\section{Figure 1}

Design and crystal structure of metal-halide cluster (MHC) based polymer. a, The molecular selfassembly design from a sophisticated $\left[\mathrm{Cu}_{4} \mathrm{I}_{4} \mathrm{P}_{4}\right]$ cluster to a cluster-based polymer; $\mathbf{b}$, The structural representation of a discrete $\mathrm{Cu}_{4}{ }_{4} \mathrm{P}_{4}$ cluster featuring $\mathrm{Cu}$-Cu metallic bonding interaction. $\mathbf{c}, \mathrm{A}$ onedimensional metallic cluster-linked polymer. 
a

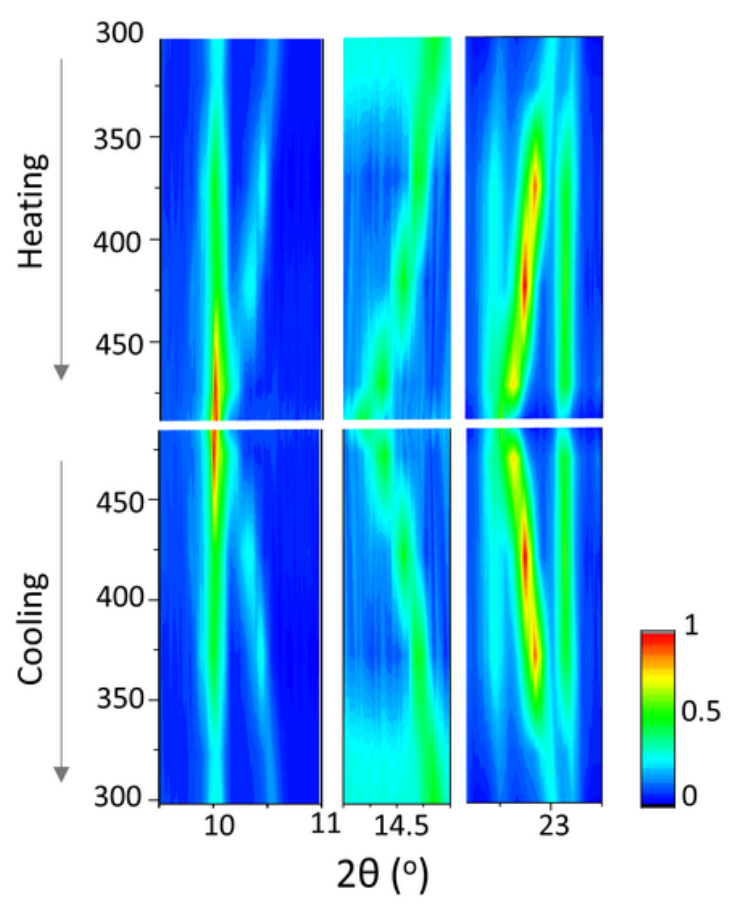

C

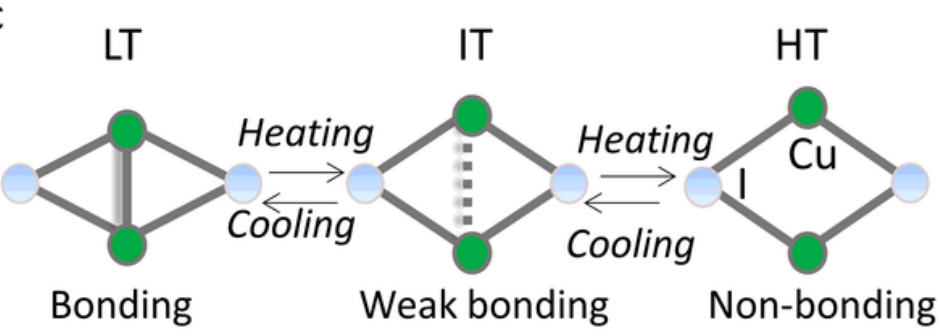

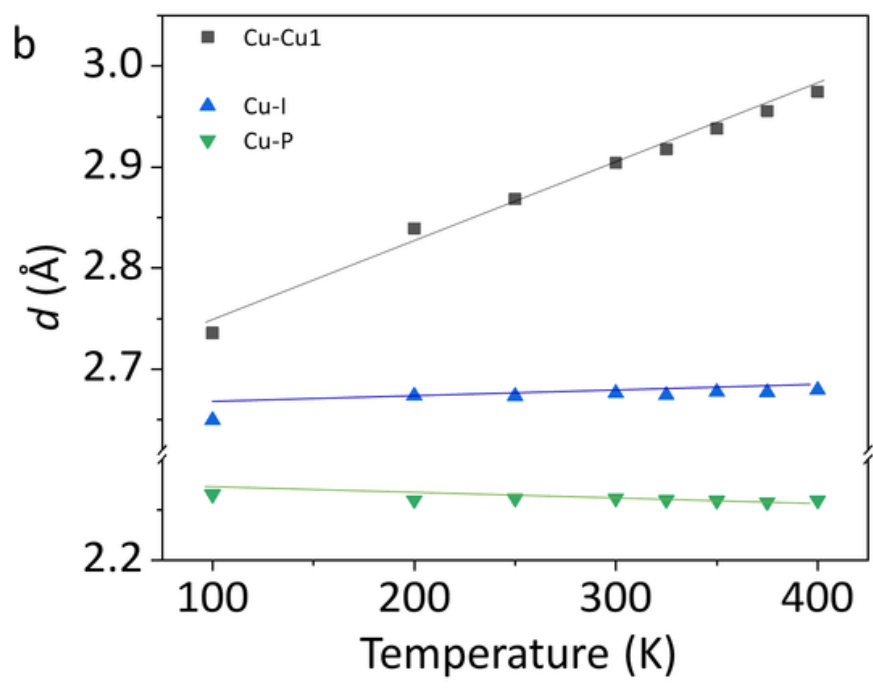

d

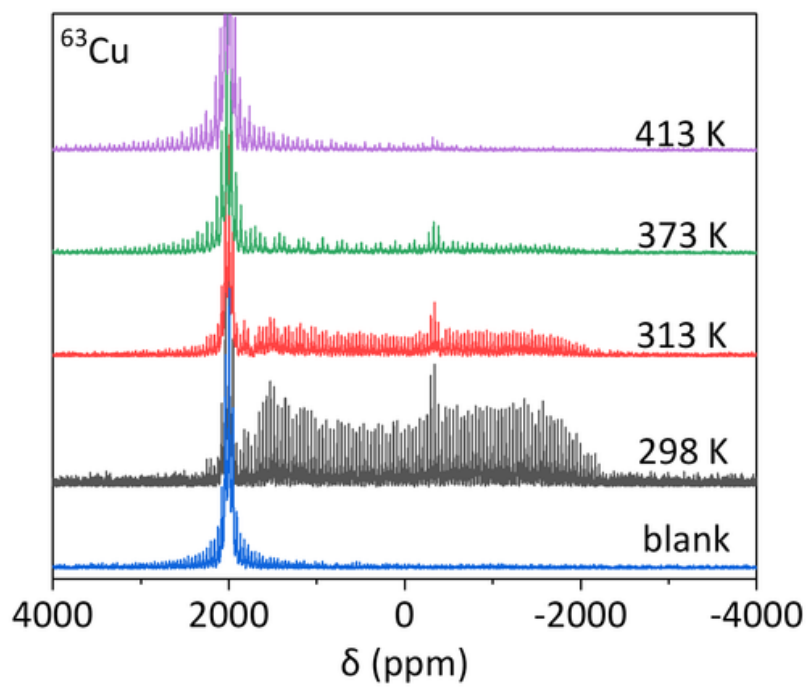

Figure 2

Characterization of electronic structural transition. a, Powder XRD patterns at selected temperatures. $\mathbf{b}$, Temperature-dependent interatomic distances in $\mathbf{b p p} \mathbf{C u}_{\mathbf{4}} \mathbf{l}_{\mathbf{4}} \mathbf{P}_{\mathbf{4}}$. $\mathbf{C}$, Schematic of dynamic bonding interaction in the $\mathrm{Cu}_{2} \mathrm{I}_{2}$ rhomboid at different temperatures. $\mathrm{LT}=$ low temperature, IT = intermediate temperature, $\mathrm{HT}=$ high temperature. $\mathbf{d}$, Solid-state static ${ }^{63} \mathrm{Cu}$ WURST-QCPMG at different temperatures. The peaks at -2000 ppm came from the artifacts in the measurements. 


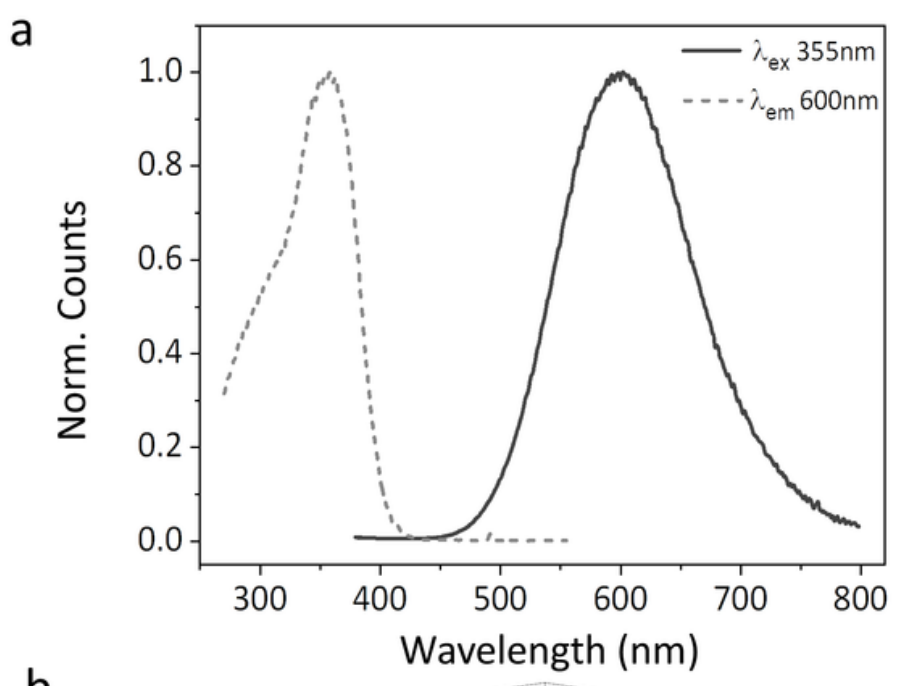

b

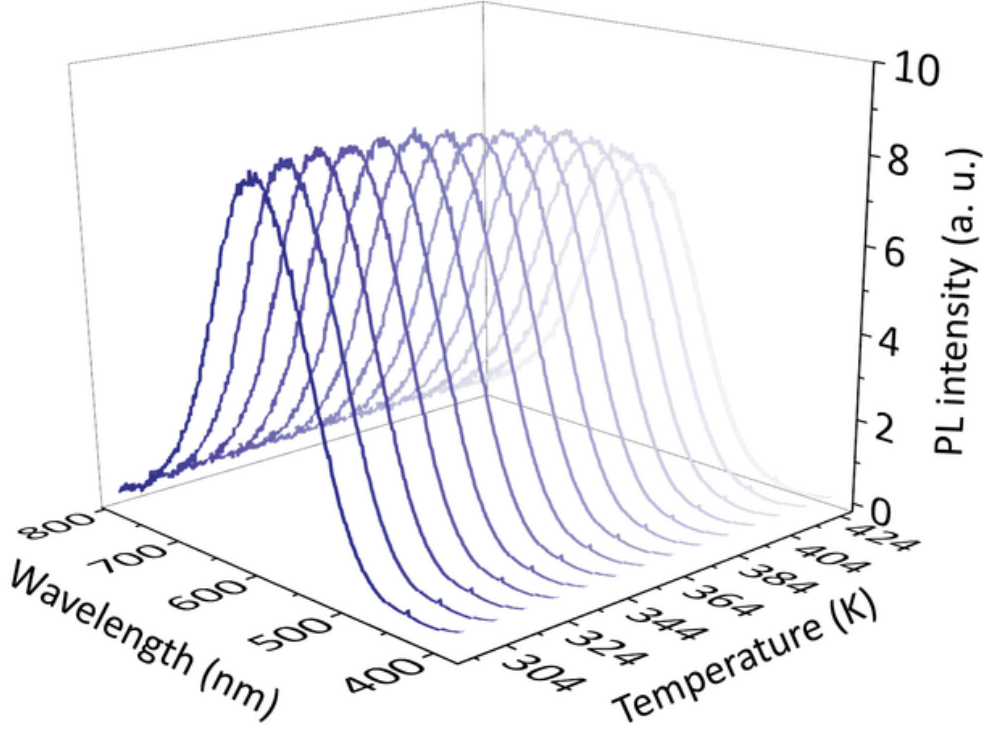

C

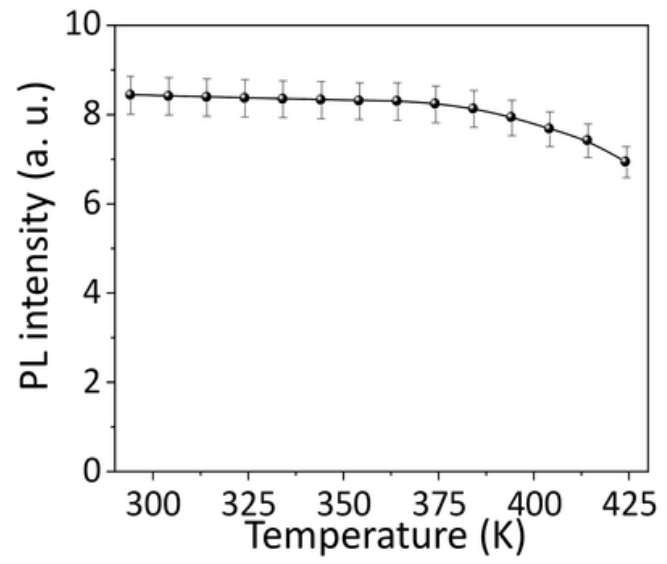

d

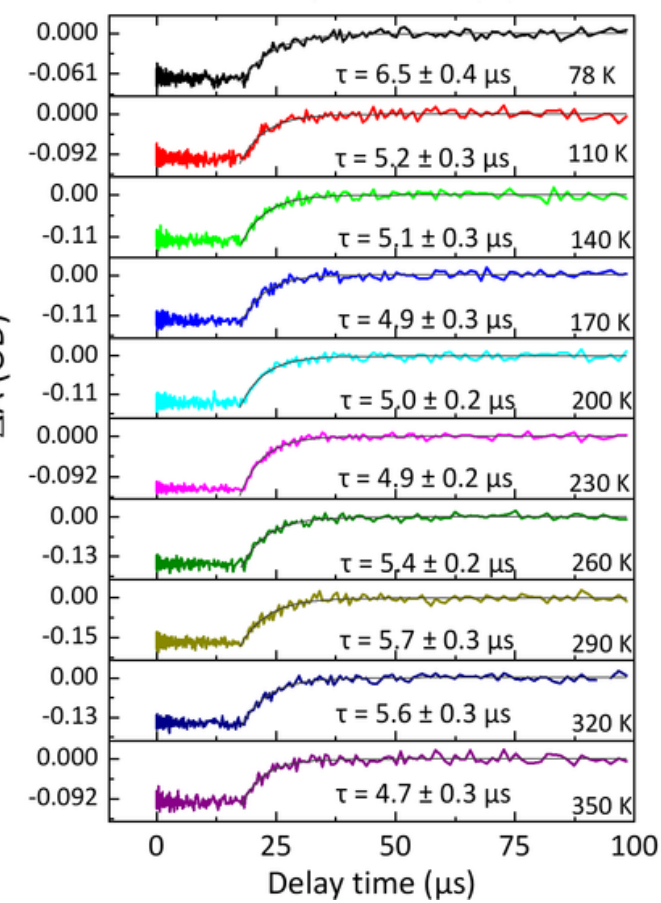

Figure 3

Spectra and zero-TQ property. a, PLE and PL spectra of bppCu $\mathbf{~}_{4} \mathbf{P}_{\mathbf{4}}$ with the excitation wavelength of 355 nm. $\mathbf{b}$, High-temperature PL emission spectra. $\mathbf{c}$, Temperature dependence of $\mathbf{b p p} \mathbf{C u}_{\mathbf{4}} \mathbf{l}_{\mathbf{4}} \mathbf{P}_{\mathbf{4}}$ in the range of 295-425 K with the error bar of $\pm 3 \%$. d, Temperature-dependent decay curves taken at emission peaks at ca. $600 \mathrm{~nm}$. 
a

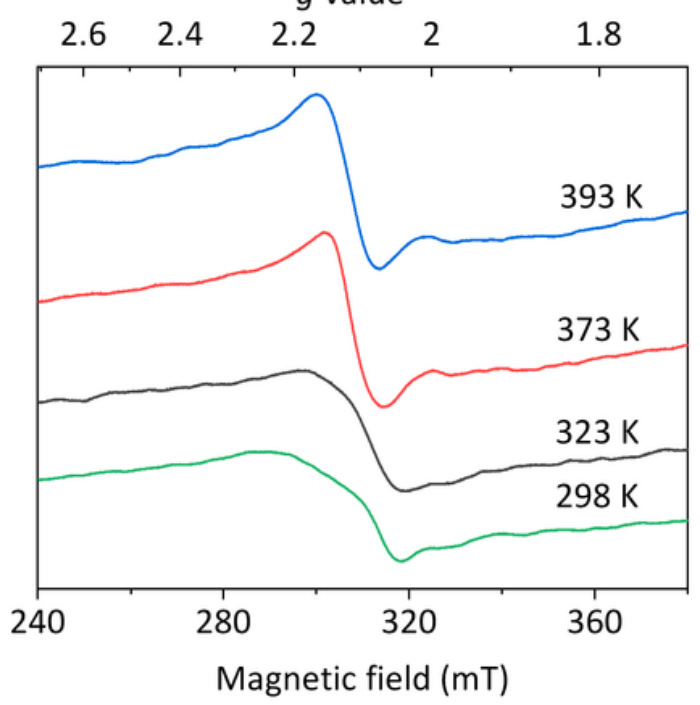

b
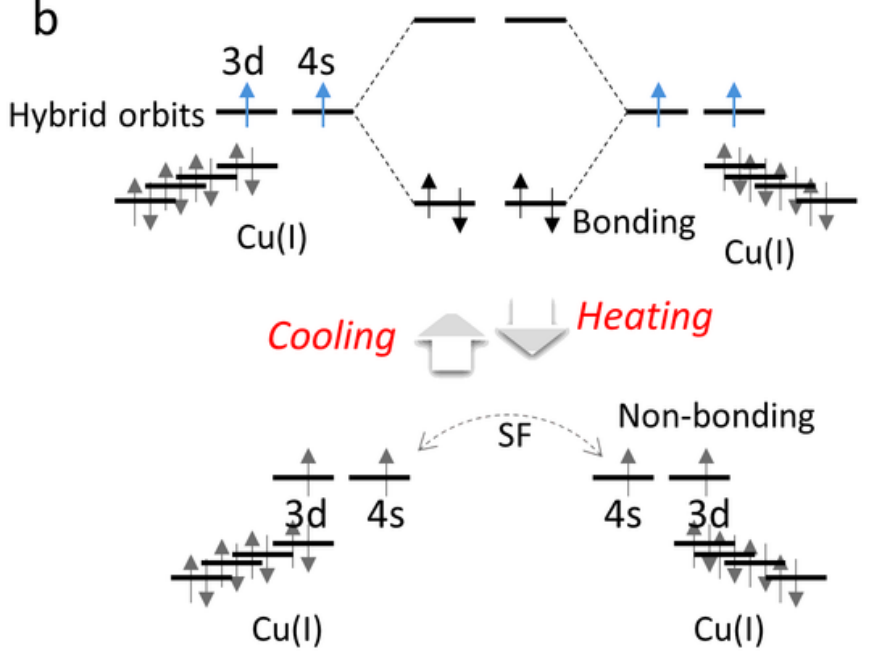

C
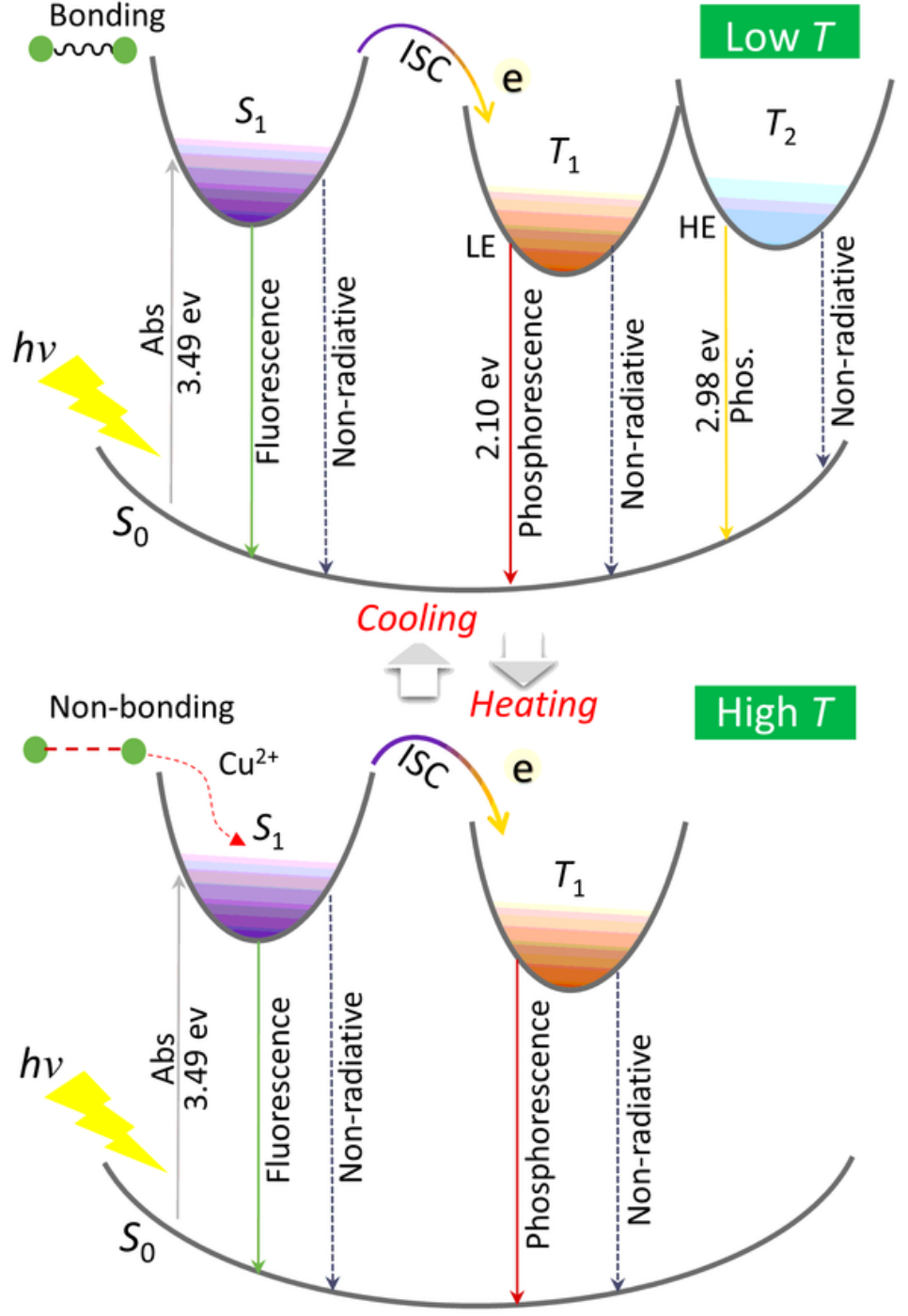

\section{Figure 4}

Zero-TQ mechanism. a, In-situ EPR spectra at different temperatures for $\mathrm{bppCu}_{4} \mathrm{I}_{4} \mathrm{P}_{\mathbf{4}}$. b, Schematic of Cu$\mathrm{Cu}$ bonding interaction at different temperatures. SF = spin flipping. $\mathbf{c}$, Energy level diagram for the lowest states and the emission decay pathways in $\mathbf{C u}_{4} \mathbf{l}_{4} \mathbf{P}_{4}$ cluster at high and low temperatures. 

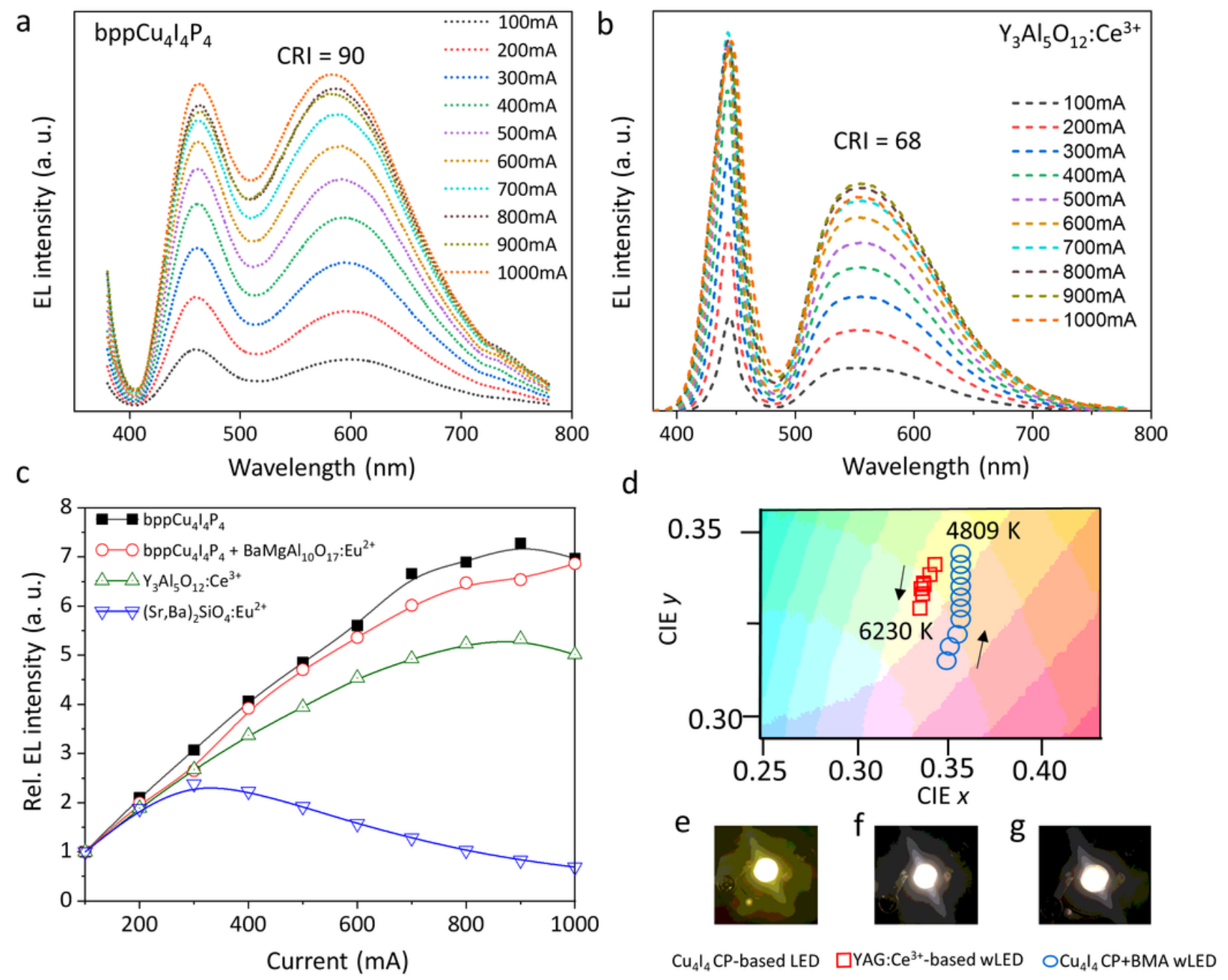

Figure 5

Performance of phosphor-converted wLEDs under high flux working current. a, EL spectra of bppCu $\mathrm{I}_{4} \mathrm{P}_{4}{ }^{-}$ based wLED with a 365-nm LED chip under a high flux operating current of 100-1,000 mA. b, EL spectra of commercial YAG:Ce ${ }^{3+}$-based wLED with a blue LED chip $\left(\lambda_{\max }=445 \mathrm{~nm}\right)$ under a high flux operating current of 100-1,000 mA. c, Current-dependent EL intensity for single-component bppCu${ }_{4} \mathrm{I}_{4} \mathrm{P}_{4}$ and its dual-component wLED as well as the commercial phosphors. $\mathbf{d}$, CIE chromaticity coordinates of the fabricated bppCu ${ }_{4} \mathrm{I}_{4} \mathrm{P}_{4}$-prototype wLED (blue circle) as well as the commercial YAG:Ce ${ }^{3+}$-based WLED (red square). $\mathbf{e}-\mathbf{g}$, Images of the fabricated bppCu${ }_{4} \mathrm{I}_{4} \mathrm{P}_{4}$ yellow LED (e), YAG:Ce ${ }^{3+}{ }_{-}(\mathbf{f})$ and $\mathrm{bppCu}_{4} \mathrm{I}_{4} \mathrm{P}_{4}$-based (g) wLED prototypes under an applied high flux working current.

\section{Supplementary Files}

This is a list of supplementary files associated with this preprint. Click to download. 
- ESIfinalv2.docx

- 400k.cif

- 325k.cif

- 200k.cif

- 375k.cif

- 300k.cif

- 250k.cif

- 350k.cif

- 100KRe.cif

- 100K.cif 